\title{
Preparation of an Amperometric Glucose Biosensor on Polyaniline-Coated Graphite
}

\author{
Shova Neupane $\mathbb{D}^{1},{ }^{1}$ Suresh Bhusal $\mathbb{D},{ }^{1}$ Vivek Subedi $\mathbb{D}^{1},{ }^{1}$ Krishna Badan Nakarmi $\mathbb{D}$, \\ Dipak Kumar Gupta $\mathbb{1}^{1,},{ }^{1,2}$ Ram Jeewan Yadav $\mathbb{1}^{3},{ }^{3}$ and Amar Prasad Yadav $\left(\mathbb{C}^{1}\right.$ \\ ${ }^{1}$ Central Department of Chemistry, Tribhuvan University, Kirtipur, Kathmandu, Nepal \\ ${ }^{2}$ Trichandra Multiple Campus, Tribhuvan University, Kathmandu, Nepal \\ ${ }^{3}$ Department of Chemistry, Prithivi Narayan Campus, Tribhuvan University, Pokhara, Nepal
}

Correspondence should be addressed to Shova Neupane; shova_n@yahoo.com and Amar Prasad Yadav; amar2y@yahoo.com

Received 22 July 2020; Revised 3 October 2020; Accepted 12 January 2021; Published 29 January 2021

Academic Editor: Sang Sub Kim

Copyright ( 2021 Shova Neupane et al. This is an open access article distributed under the Creative Commons Attribution License, which permits unrestricted use, distribution, and reproduction in any medium, provided the original work is properly cited.

\begin{abstract}
Control of glucose concentration has tremendous significance in medical diagnosis, pharmaceuticals, food, and fermentation industries. Herein, we report on the fabrication of a facile, low-cost, and sensitive enzyme-based amperometric sensor using the electrochemically deposited polyaniline (PANI) film on a graphite electrode. PANI was deposited from an aqueous solution of $0.2 \mathrm{M}$ aniline in $1.0 \mathrm{M}$ hydrocholoric acid $(\mathrm{HCl})$ by cyclic voltammetry $(\mathrm{CV})$. Surface morphology and composition characterization of the PANI film were carried out by scanning electron microscopy (SEM), X-ray photoelectron spectroscopy (XPS), and Fourier-transform infrared (FTIR) spectroscopy. Potentiostatic immobilization of glucose oxidase $\left(\mathrm{GO}_{\mathrm{X}}\right)$ enzyme in the PANI film was carried out at $0.75 \mathrm{~V}$ to fabricate an amperometric glucose biosensor (GOx/PANI/graphite biosensor). The glucose concentration response of the prepared sensor was studied amperometrically by detecting hydrogen peroxide $\left(\mathrm{H}_{2} \mathrm{O}_{2}\right)$. The detection of $\mathrm{H}_{2} \mathrm{O}_{2}$ was optimized by calibrating the effects of $\mathrm{pH}$, reduction potential, and background current. A reduction potential of $-0.4 \mathrm{~V}$ at $\mathrm{pH} 6$ was the best combination to get a maximum amperometric response of the GOx/PANI/graphite biosensor. A stable current response was obtained in $4 \mathrm{~min}$ with a high reproducibility in linearity within the concentration range of $0.01 \mathrm{M}-0.1 \mathrm{M}$ D-glucose. Therefore, the fabricated GOx/PANI/graphite biosensor could be a promising candidate for glucose sensing.
\end{abstract}

\section{Introduction}

Glucose concentration measurement is immensely important in food processing, fermentation reactors, pharmaceuticals processes, textile industry, environmental monitoring, and clinical laboratories [1-3]. Rapid determination of blood sugar is essential in the treatment and control of diabetes. There are numerous methods in practice for glucose determination, such as high-performance liquid chromatography (HPLC), polarimetry, capillary electrophoresis, gas chromatography, colorimetry, electrochemiluminescence, and biosensors $[4,5]$. The use of glucose biosensors is preferred in the recent past due to its low cost, reliability, fast, and accurate response. The glucose biosensor based on the amperometric method is relatively a better method and easy to fabricate in the laboratory $[6,7]$.
The response of a glucose biosensor requires enzyme immobilization on the electrode surface. The surface used for immobilization should facilitate a smooth transfer of an electron from a biocomponent to the electrode surface, and therefore, it should impart biocompatibility to the electrode surface [8]. It should also enhance the response properties and be sensitive to perturbation so that a response is correctly recorded $[8,9]$. In this regard, intrinsically conducting polymers containing self- - -conjugated system with either a double or a single bond alternating along the polymer chain have promising properties to be used in biosensing. The continuous conjugation in conductive polymers is responsible for remarkable electrochemical properties such as high electrical conductivity, low ionization potential, high electron affinities, and low energy optical transition [10-13]. Among conducting polymers, polyaniline (PANI) has gained keen 
interest among researchers due to its dual nature as it creates an immobilization platform for biomolecules and acts as an electron mediator in enzymatic reactions the same time. Such properties make PANI the right candidate for biosensing applications [14-17]. It provides a high surface area and can be quickly deposited on the electrode surface with controlled film thickness [18].

Enzyme immobilization is tempting the researchers as it forms stronger adhesion between the enzyme and the matrix. In combination with a glucose oxidase enzyme (GOx), PANI is a potent combination of glucose sensors [15]. The $\mathrm{GO}_{\mathrm{x}}$ adsorbed nicely on PANI by electrostatic interaction due to its negative charge. Such entrapment maintains the accessibility of catalytic sites and prevents the enzyme from leaching [19-22]. GOx is a dimeric protein containing one tightly bound flavin adenine dinucleotide (FAD) per monomer as a cofactor. Therefore, each enzyme has two FAD sites. The FAD can be released from the protein following the protein's partial unfolding since it is not covalently bound. The GOx-based biosensor catalyzes glucose's oxidation in the presence of oxygen to produce gluconolactone, which is hydrolyzed to gluconic acid and hydrogen peroxide $\left(\mathrm{H}_{2} \mathrm{O}_{2}\right)[23,24]$.

$$
\text { Glucose }+\mathrm{O}_{2} \stackrel{\text { GOx }}{\longrightarrow} \mathrm{H}_{2} \mathrm{O}_{2}+\text { Gluconic acid }
$$

The $\mathrm{H}_{2} \mathrm{O}_{2}$ can further be oxidized or reduced and either way is used for glucose detection. Therefore, surface modification of electrode by a polymeric membrane is an ongoing research approach for improving the sensor's response.

This paper describes a simple glucose biosensor fabricated by electropolymerization of aniline on graphite substrate and potentiostatic immobilization of GOx onto the PANI film on the graphite surface. A quantification of glucose concentration has been achieved by optimizing the response of the biosensor with $\mathrm{pH}$, reduction potential, response time, and background current for the reduction of hydrogen peroxide obtained from enzyme-catalyzed oxidation of glucose.

\section{Materials and Methods}

2.1. Chemicals and Reagents. Analytical reagent grade aniline $\left(\mathrm{C}_{6} \mathrm{H}_{5} \mathrm{NH}_{2}\right)$, glucose oxidase $(\mathrm{GOx})$, sodium monohydrogen orthophosphate $\left(\mathrm{NaH}_{2} \mathrm{PO}_{4 \cdot 2} \mathrm{H}_{2} \mathrm{O}\right)$, and $\mathrm{D}(+)$ glucose was purchased from Merck, USA. Hydrogen peroxide $\left(\mathrm{H}_{2} \mathrm{O}_{2}\right)$, hydrochloric acid $(\mathrm{HCl})$, and potassium nitrate $\left(\mathrm{KNO}_{3}\right)$ were acquired from Fischer Scientific, India. Similarly, a graphite rod of $99.99 \%$ purity was received from Nilako Corp., Japan. $1.0 \mathrm{M}$ and $2.0 \mathrm{M} \mathrm{HCl}, 0.2 \mathrm{M} \mathrm{C}_{6} \mathrm{H}_{5} \mathrm{NH}_{2}$, and $0.1 \mathrm{M} \mathrm{KNO}_{3}$ solutions were prepared in double-distilled water. Also, buffer solutions of $\mathrm{pH}$ 5.0, 5.5., 6.0, 6.5, and 7.0 were adapted with a standard buffer preparation method [25].

2.2. Electrochemical Synthesis of PANI onto the Graphite Electrode. A graphite rod was polished with silicon carbide (SiC) paper starting from \#1200 grit size down to \#2000 and ultrasonicated in double-distilled water for $10 \mathrm{~min}$. It was then washed with distilled water and dried with compressed air. The electropolymerization of aniline on the graphite electrode was performed at room temperature (RT) using cyclic voltammetry (CV) in $\mathrm{HCl}$. A saturated calomel electrode (SCE) was used as a reference and a Pt wire as a counter electrode. All the potential mentioned hereafter referred to SCE. The $\mathrm{CV}$ was carried out in the potential range of $-0.4 \mathrm{~V}$ to $1.2 \mathrm{~V}$ at a $100 \mathrm{mV} / \mathrm{sec}$ scan rate for 10 cycles. Freshly prepared PANI/graphite electrode was washed with a buffer solution, dried under the compressed air, and used for immobilizing the enzyme. The process of PANI formation on the graphite electrode can be represented as

$$
\text { Aniline }+\mathrm{HCl} \stackrel{\text { Graphite Electrode }}{\longrightarrow} \text { PANI/Graphite }
$$

2.3. Characterization of the PANI Film. PANI film on the graphite surface was analyzed by X-ray photoelectron spectroscopy (XPS) (Thermo scientific sigma probe instrument) with a vacuum condition around $2 \times 10^{-8}$ mbar with $\mathrm{Al} \mathrm{K \alpha}$ $(1486.6 \mathrm{eV})$ at $400 \mu \mathrm{m}$ beam size. Pass energy of $50 \mathrm{eV}$ at the resolution of $0.1 \mathrm{eV}$ was used for each scan. The surface was sputtered by $\mathrm{Ar}^{+}$at $1.0 \mathrm{KeV}$ for $2 \mathrm{~min}$ before each characterization to clean the surface. The spectra were decomposed with CasaXPS [26]. Similarly, the surface functionality of the prepared PANI was characterized by Fourier-transform infrared spectroscopy (FTIR) (Shimadzu Tracer-100) in the wavelength of $400-4000 \mathrm{~cm}^{-1}$. Alike, the morphology of PANI was observed by scanning electron microscopy (SEM) (Hitachi SU 8000).

2.4. The PANI/Graphite Electrode Response to Hydrogen Peroxide $\left(\mathrm{H}_{2} \mathrm{O}_{2}\right)$. The response of the PANI/graphite electrode to $\mathrm{H}_{2} \mathrm{O}_{2}$ was optimized concerning $\mathrm{pH}$ and potential. $\mathrm{pH}$ was optimized by recording the reduction current of $\mathrm{H}_{2} \mathrm{O}_{2}$ at $-0.40 \mathrm{~V}$ in a phosphate buffer solution of $\mathrm{pH} 5.0$, $5.5,6.0,6.5$, and 7.0 with $0.1 \mathrm{M} \mathrm{KNO}_{3}$ as a supporting electrolyte. A steady background current was also measured at $-0.4 \mathrm{~V}$ without $\mathrm{H}_{2} \mathrm{O}_{2}$. Then, a reduction current at every addition of $\mathrm{H}_{2} \mathrm{O}_{2}$ was measured in the concentration range $1.0 \mathrm{mM}$ to $25 \mathrm{mM}$. The difference in the current value $\left(\Delta i=i_{b}-i_{a}\right)$ against the $\mathrm{H}_{2} \mathrm{O}_{2}$ concentration was determined, where $\Delta i$ is the difference of current, $i_{b}$ is the total current,and $i_{a}$ is the steady background current.

The electrolyte was stirred uniformly by a PTFE covered magnetic bar during the experiment to get a rapid and reproducible current response. The optimization of potential used for cathodically reducing $\mathrm{H}_{2} \mathrm{O}_{2}$ was done by performing the experiment mentioned above at a fixed $\mathrm{pH}(\mathrm{pH}$ 6.0) so that the optimized potential will be used in amperometric determination of glucose concentration.

2.5. Glucose Oxidase (GOx) Immobilization on the PANI/Graphite Electrode. The immobilization of GOx on the PANI/graphite electrode was carried out potentiostatically at $0.75 \mathrm{~V}$ for $40 \mathrm{~min}$ in a $0.1 \mathrm{M}$ phosphate buffer solution ( $\mathrm{pH}$ 6.0) containing $200 \mathrm{U} / \mathrm{mL}$ GOx and $0.1 \mathrm{M} \mathrm{KNO}_{3}$ as a supporting electrolyte. Then, the film was carefully rinsed with distilled water to remove unattached enzyme. The 


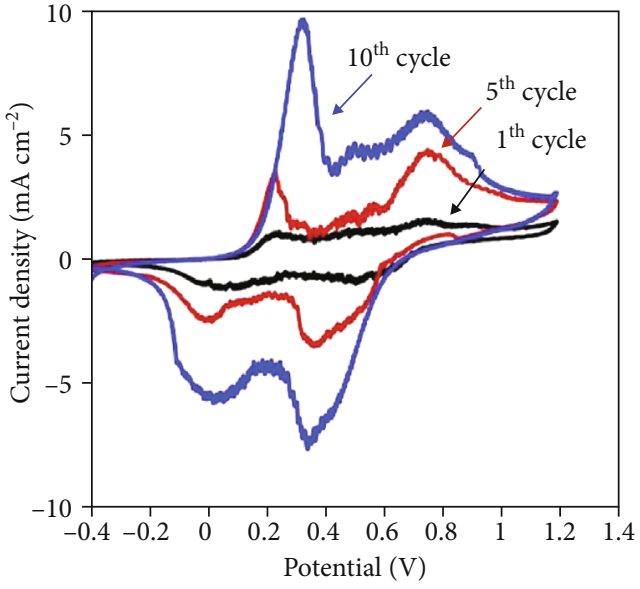

Figure 1: Cyclic voltammogram of the PANI/graphite surface. Experimental conditions: $0.2 \mathrm{M}$ aniline monomer in $1.0 \mathrm{M} \mathrm{HCl}$, potential limit $-0.4-1.2 \mathrm{~V}$, scan rate: $10 \mathrm{mV} / \mathrm{s}^{-1}$, number of cycles $=10$.

prepared electrode is named as GOx/PANI/graphite biosensor in this article, and the process can be summarized as

PANI/Graphite $\stackrel{\text { Potentiostatic Immobilization of GOx }}{\longrightarrow}$ GOx/PANI/Graphite

2.6. Amperometric Response Measurements of Glucose Oxidation. The amperometric response of the prepared biosensor was studied by monitoring the concentration of $\mathrm{D}(+)$ glucose oxidized by GOx and response measured in terms of cathodic current due to $\mathrm{H}_{2} \mathrm{O}_{2}$ reduction. The GOx/$\mathrm{PANI} /$ graphite electrode was immersed in $0.1 \mathrm{M}$ phosphate buffer of $\mathrm{pH} 6.0$ containing $0.1 \mathrm{M} \mathrm{KNO}_{3}$ as a supporting electrolyte. A potential of $-0.4 \mathrm{~V}$ was applied to the electrode, and a stable background current was measured. After the background current reached a stable value, D (+) glucose solution was added dropwise to the buffer solution by using a micropipette. The oxidation of glucose by GOx resulted in the formation of $\mathrm{H}_{2} \mathrm{O}_{2}$, which was reduced at $-0.4 \mathrm{~V}$. The measurements were performed under hydrodynamic amperometric mode to have a faster and reproducible response. The response time of the biosensor was also optimized.

\section{Results and Discussion}

3.1. Electrochemical Synthesis of PANI onto the Graphite Electrode by $C V$. Figure 1 shows the cyclic voltammogram of PANI deposition on a graphite electrode. Three subsequent peaks observed in the potential range studied show that the PANI is redox-active. The first peak appeared at a $0.20 \mathrm{~V}$ potential, representing the transformation of sufficiently reduced form of leucomeraldine into a partly oxidized emeraldine state. The peak occurring at approximately $0.80 \mathrm{~V}$ corresponds to emeraldine transformation into perningraniline, the fully oxidized form of polyaniline [27]. The redox peaks at $0.50 \mathrm{~V}$ appeared between the two dominant peaks is generally attributed to the transformation of hydroquinone to p-benzoquinone [28]. The leucomeraldine form has nitro- gen atoms in the amine state, whereas all nitrogen atoms in perningraniline are in the imine state. These two forms are not conductive. The conductive form is obtained when the ratio of amine to imine nitrogen is 1 and depending on the $\mathrm{pH}$ value.

3.2. Characterization of PANI. Surface composition of the PANI/graphite electrode was characterized by XPS measurement. A thick PANI coating was developed for the XPS analysis in order to avoid the graphite substrate detection, and the electrode was rinsed with water and ethanol to avoid mass protonation. High-resolution spectra of $\mathrm{C} 1 \mathrm{~s}$ and N1s are generally used to understand the state of PANI. Figure 2(a) shows the high-resolution C1s spectra together with four symmetric deconvoluted peaks. The C1s peaks at $284.75 \mathrm{eV}$, $285.49 \mathrm{eV}, 286.44 \mathrm{eV}$, and $288.81 \mathrm{eV}$ appeared after fitting. The main peak at $284.75 \mathrm{eV}$ is attributed to the $\mathrm{C}-\mathrm{C} / \mathrm{C}-\mathrm{H}$ groups present in the aniline polymer. The peak at $285.49 \mathrm{eV}$ is due to the $\mathrm{CN} / \mathrm{C}=\mathrm{N}$ groups. Similarly, the peak observed at $286.49 \mathrm{eV}$ is related to the $\mathrm{CN}^{+} / \mathrm{C}=\mathrm{N}^{+}$groups. The peak at $288.81 \mathrm{eV}$ might contain $\mathrm{C}=\mathrm{O} / \mathrm{C}-\mathrm{O}$ groups due to the contaminations $[29,30]$. The two dominated peaks at $284.75 \mathrm{eV}(\mathrm{C}-\mathrm{C} / \mathrm{C}-\mathrm{H})$ and $285.49 \mathrm{eV}(\mathrm{CN} / \mathrm{C}=\mathrm{N})$ account for approximately $36 \%$ and $35 \%$ contributions from PANI. The peak at $286.49 \mathrm{eV}$ for $\mathrm{CN}^{+} / \mathrm{C}=\mathrm{N}^{+}(15 \%)$ represents the extensive polymerization of aniline for PANI formation. A relatively high percentage of $\mathrm{C}-\mathrm{C} / \mathrm{C}-\mathrm{H}$ and $\mathrm{CN} / \mathrm{C}=\mathrm{N}$ might also indicate for the mixed state, emeraldine, of PANI.

N1s spectra provide more precise information about the PANI structure since amine, imine, and protonated nitrogen can be distinguished (Figure 2(b)). The N1s spectra show three asymmetrical peaks located at $399.1 \mathrm{eV}, 399.8 \mathrm{eV}$, and $401.86 \mathrm{eV}$, which are assigned for neutral imine, amine, and positively charged nitrogen, respectively [31-33]. The tentative compositional ratio of the three nitrogen compounds imine, amine, and a positively charged nitrogen are $30 \%$, $60 \%$, and $10 \%$, respectively. A large and broad signal at high binding energy is indicative of positively charged nitrogen atom $\mathrm{N}^{+}$. The preferential protonation of imine sites, which are more basic, has resulted in a relatively reduced imine component. This result further confirmed the emeraldine as a dominant form in the coated layer.

Figure 2(c) represents a SEM image of the PANI/graphite surface. The deposition of tiny particles of PANI in rod-like shape is apparent. Also, spherical agglomerations of these particles forming coral-like island structure are present. Such a structure is assumed to be a good site for the immobilization of enzymes. Figure 2(d) shows the FTIR spectrum of PANI/graphite. The FTIR peaks at $1600 \mathrm{~cm}^{-1}$ and $1490 \mathrm{~cm}^{-1}$ show $\mathrm{C}=\mathrm{C}$ stretching vibration of a quinoid structure and a benzene ring, respectively. Similarly, the characteristic peaks at $1302 \mathrm{~cm}^{-1}, 1150 \mathrm{~cm}^{-1}$, and $810 \mathrm{~cm}^{-1}$ suggest stretching vibration of $\mathrm{C}-\mathrm{N}, \mathrm{C}=\mathrm{N}$, and $\mathrm{C}-\mathrm{H}$ inplane. These values are in agreement with the reported values elsewhere [34-36].

3.3. Response of the PANI/Graphite Electrode to $\mathrm{H}_{2} \mathrm{O}_{2}$. The glucose biosensor works based on detecting $\mathrm{H}_{2} \mathrm{O}_{2}$. Therefore, optimization of the PANI/graphite electrode response to 


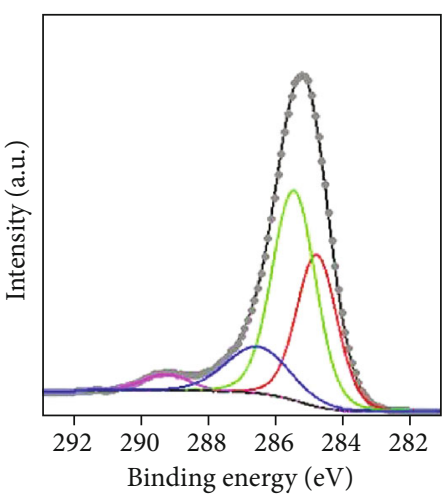

(a)

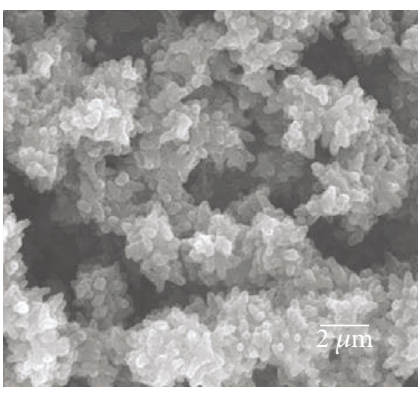

(c)

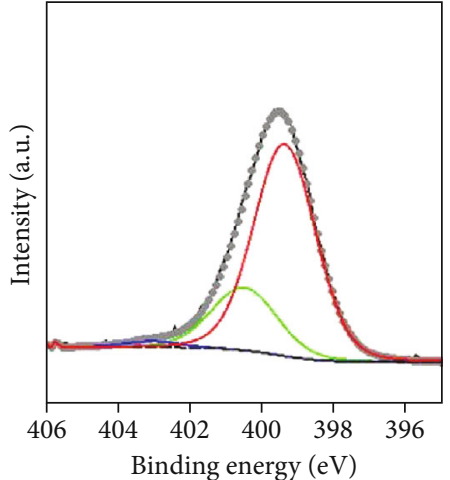

(b)

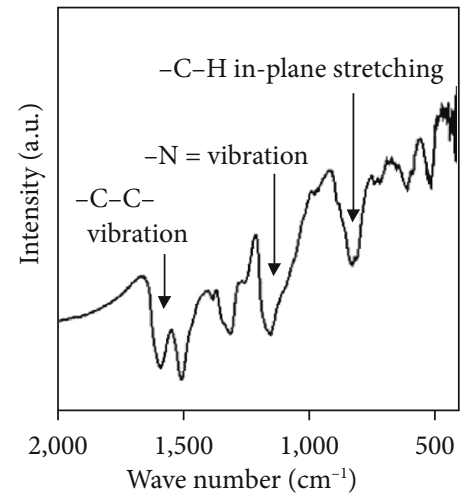

(d)

FIgURe 2: (a) High-resolution XPS spectra of C1s, (b) N1s of the PANI/graphite electrode, (c) SEM image of PANI, and (d) FTIR of the PANI/graphite electrode.

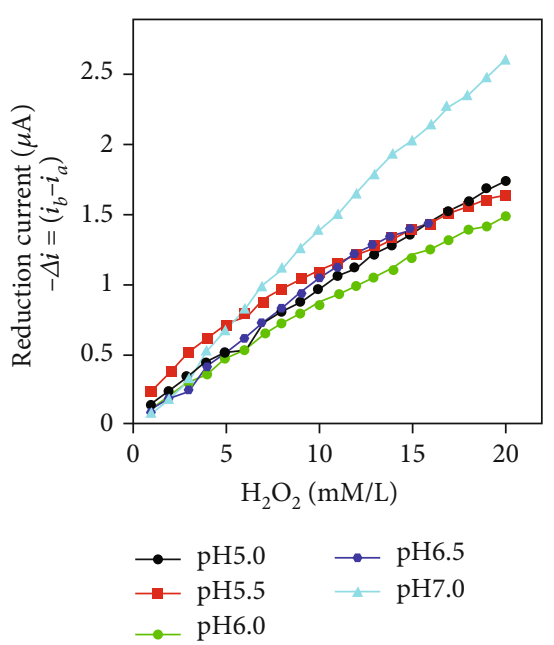

Figure 3: Reduction current vs. concentration of $\mathrm{H}_{2} \mathrm{O}_{2}$ at different $\mathrm{pH}$ on the PANI/graphite electrode.

$\mathrm{H}_{2} \mathrm{O}_{2}$ at different $\mathrm{pH}$ was essential. In this regard, the reduction potential for $\mathrm{H}_{2} \mathrm{O}_{2}$ was set at -0.4 , and the resulting current with variable $\mathrm{H}_{2} \mathrm{O}_{2}$ concentrations at different $\mathrm{pH}$ was being measured. The reduction of $\mathrm{H}_{2} \mathrm{O}_{2}$ takes place as

$$
\mathrm{H}_{2} \mathrm{O}_{2}+2 \mathrm{H}^{+}+2 \mathrm{e}^{-} \stackrel{-0.4 \mathrm{~V}}{\longrightarrow} 2 \mathrm{H}_{2} \mathrm{O}
$$

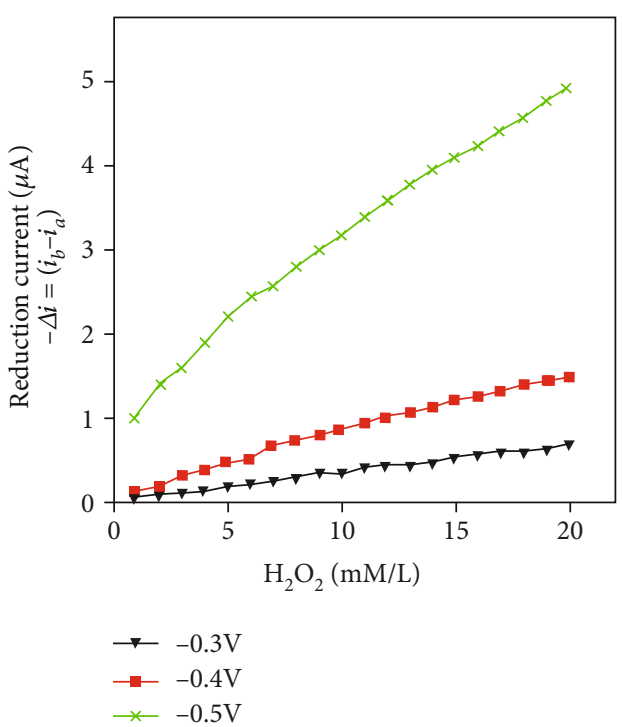

FIgURE 4: Reduction current vs. concentration of $\mathrm{H}_{2} \mathrm{O}_{2}$ at the $\mathrm{PANI} /$ graphite electrode at various applied potentials of $-0.3 \mathrm{~V}$, $-0.4 \mathrm{~V}$, and $-0.5 \mathrm{~V}$ at $\mathrm{pH} 6.0$.

A graphical representation of the response current of the PANI/graphite electrode against $\mathrm{H}_{2} \mathrm{O}_{2}$ concentrations at different $\mathrm{pH}$ is shown in Figure 3. A linear current response with $\mathrm{H}_{2} \mathrm{O}_{2}$ concentration except $\mathrm{pH} 5$ is observed. It is worth mention that the optimum $\mathrm{pH}$ stability range for GOx 


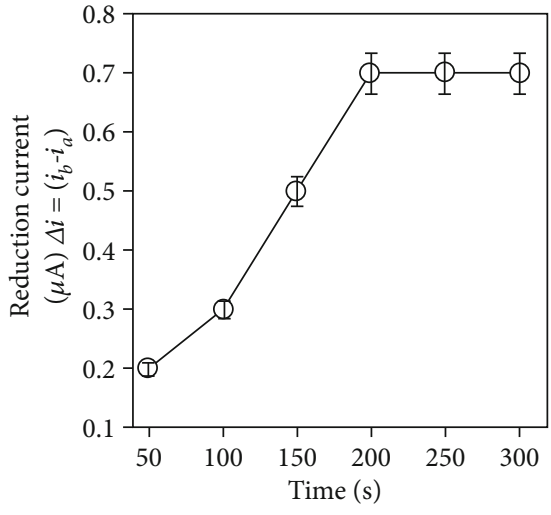

(a)

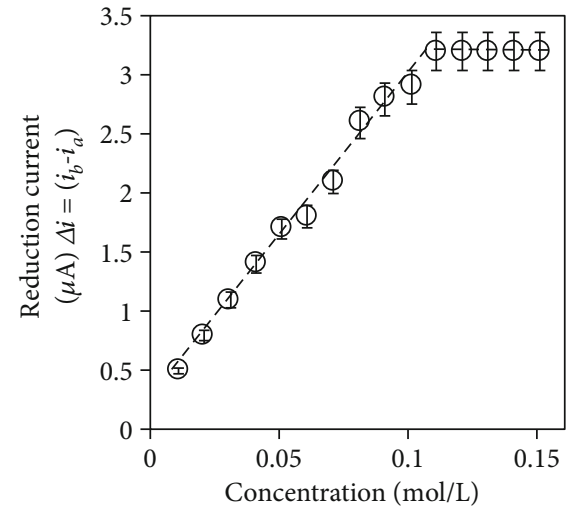

(b)

Figure 5: Response of biosensor: (a) reduction current vs. time and (b) reduction current vs. concentration of glucose.

enzyme is $\mathrm{pH} 5.5$ to 7.0 . From the current response, the pH6.0 was selected for biosensor response measurement due to the better conductivity and stability of polyaniline in a slightly acidic medium. The enzyme GOx is also stable in this $\mathrm{pH}$, and $\mathrm{H}_{2} \mathrm{O}_{2}$ can be reduced.

3.4. Effect of $\mathrm{H}_{2} \mathrm{O}_{2}$ Reduction Potential on the Response of the PANI/Graphite Electrode. After optimizing the $\mathrm{pH}$ for $\mathrm{H}_{2} \mathrm{O}_{2}$ reduction, the next step was to scrutinize the reduction potential for obtaining an optimum test condition for $\mathrm{H}_{2} \mathrm{O}_{2}$ reduction. The potential of the $\mathrm{PANI} /$ graphite electrode was set at $-0.3,-0.4$, and $-0.5 \mathrm{~V}$, at the fixed $\mathrm{pH} 6.0$ in each measurement. From the plot in Figure 4, the response current is found to increase with potential becoming negative. However, at $-0.5 \mathrm{~V}$, a nonlinear current is obtained at a lower concentration of $\mathrm{H}_{2} \mathrm{O}_{2}$, which can be detrimental in the lower detection limit of the sensor. Therefore, an optimum response is chosen at $-0.4 \mathrm{~V}$ with the view that it also reduces the effect of interferences, and that a better sensitivity of the enzyme could be possible.

3.5. Response of the GOx/PANI/Graphite Biosensor. After immobilization of GOx in PANI/graphite, the response of the electrode towards glucose oxidation was studied by measuring the reduction current of $\mathrm{H}_{2} \mathrm{O}_{2}$ produced from glucose oxidation catalyzed by the enzyme GOx. First of all, the time taken for a stable current response in the presence of a fixed amount of $\mathrm{D}(+)$ glucose at $\mathrm{pH} 6.0$ buffer solution was studied. Figure 5(a) shows initially the current increased gradually, and a steady current obtained after $4 \mathrm{~min}$. Therefore, the time required to get a total oxidation of glucose by $\mathrm{GOx}$ and subsequent reduction of $\mathrm{H}_{2} \mathrm{O}_{2}$ is 4 min.

After evaluating the response time of the biosensor, its response to glucose concentration was studied. Figure 5(b) represents a response of glucose biosensor against D (+) glucose concentration. A linear response is obtained within the concentration range of $0.01 \mathrm{M}$ to $0.1 \mathrm{M}$. Above $0.1 \mathrm{M}$ concentration, the current became constant due to saturation of electrode surface, and therefore, the biosensor response could not be used to quantify the glucose concentration. The linearity clearly shows that lower detection limit can be easily brought down by measuring the lower current values.
When the glucose solution is added, it is oxidized by GOx of the $\mathrm{GO}_{\mathrm{X}} / \mathrm{PANI} /$ graphite electrode into the gluconic acid and $\mathrm{H}_{2} \mathrm{O}_{2}$. This hydrogen peroxide is detected at $-0.4 \mathrm{~V}$ due to a cathodic response. The overall response of the sensor toward hydrogen peroxide can be written as

$$
\begin{aligned}
& \text { Glucose }+ \mathrm{O} 2+\mathrm{GOx} / \mathrm{PANI} / \text { Graphite } \stackrel{\text { Immobilization }}{\longrightarrow} \\
& \text { GOx/PANI/Graphite + Gluconolactone }+\mathrm{H} 2 \mathrm{O} 2
\end{aligned}
$$

The fundamental concept of the glucose biosensor is that the immobilized GOx catalyses the oxidation of glucose to gluconolactone and hydrogen peroxide by molecular oxygen as an electron acceptor. In this process, gluconolactone is nonenzymatically hydrolysed to gluconic acid. GOx, working as a catalyst, needs a redox cofactor-flavin adenine dinucleotide (FAD). FAD acts as the initial electron acceptor and is reduced to $\mathrm{FADH}_{2}$. The $\mathrm{FADH}_{2}$ is then oxidized by dissolved $\mathrm{O}_{2}$ producing $\mathrm{H}_{2} \mathrm{O}_{2}$ and transforming the enzyme to its initial state containing FAD [37-39].

$$
\begin{gathered}
\text { Glucose }+\mathrm{GO}_{\mathrm{x}}+\mathrm{FAD} \longrightarrow \text { Glucolactone }+\mathrm{GO}_{\mathrm{x}}+\mathrm{FADH}_{2} \\
\mathrm{GO}_{\mathrm{x}}+\mathrm{FADH}_{2}+\mathrm{O}_{2} \longrightarrow \mathrm{GO}_{\mathrm{x}}+\mathrm{FAD}+\mathrm{H}_{2} \mathrm{O}_{2}
\end{gathered}
$$

It can be expected that the reversible two-electron redox reaction takes place at the GOx/PANI/graphite electrode that is attributed to $\mathrm{FAD}$, which is tightly bonded to the active site of the GOx, and/or to FAD, which is loosely bonded to the active site of the GOx or is even diffused for the GOx active site [40]. The electrode easily recognizes the number of electron transfers, and this electron flow is proportional to the number of glucose molecules. Alternatively, an electrontransfer mediator, which has a lower oxidation potential, can bridge the electrical communication between glucose oxidase and glucose.

The results show that by correlating with the response current, the concentration of glucose is analyzed. The concentration analyzed by thus fabricated amperometric biosensor is comparable to other reported glucose biosensors $[1,15$, 
$22,24]$, and hence, it can be recommended for practical application for glucose determination.

\section{Conclusion}

This study describes the fabrication of a simple, sensitive, and low-cost glucose sensor $\left(\mathrm{GO}_{\mathrm{X}} / \mathrm{PANI} /\right.$ graphite $)$ by employing conducting polymer as an entrapment surface for the enzyme. The electrodeposited polyaniline surface has a coral-like island structure, making it a good site for the immobilization of enzymes. The sensor gives an optimum amperometric response to $\mathrm{D}(+)$ glucose in the concentration range of $0.01 \mathrm{M}-0.1 \mathrm{M}$ at $\mathrm{pH} 6.0$ and the potential of $-0.4 \mathrm{~V}$. A stable sensor response is obtained in $4 \mathrm{~min}$, and it gives reproducible results.

\section{Data Availability}

The additional data and information of this study are available from the corresponding author upon reasonable request.

\section{Conflicts of Interest}

The authors declare no competing interests.

\section{Acknowledgments}

The authors are thankful to the Central Department of Chemistry, Tribhuvan University, Kathmandu, Nepal, for providing the facilities for the completion of the work. National Institute of Materials Science, Tsukuba, Japan, is acknowledged for allowing to carry out XPS, FTIR, and SEM measurements. The project was funded by the Central Department of Chemistry, Tribhuvan University, Kirtipur, Kathmandu, Nepal.

\section{References}

[1] S. -R. Lee, Y.-T. Lee, K. Sawada, H. Takao, and M. Ishida, "Development of a disposable glucose biosensor using electroless-plated $\mathrm{Au} / \mathrm{Ni} /$ copper low electrical resistance electrodes," Biosensors \& Bioelectronics, vol. 24, no. 3, pp. 410414, 2008.

[2] S. Liu and H. Ju, "Reagentless glucose biosensor based on direct electron transfer of glucose oxidase immobilized on colloidal gold modified carbon paste electrode," Biosensors \& Bioelectronics, vol. 19, no. 3, pp. 177-183, 2003.

[3] Z. Wang, S. Liu, P. Wu, and C. Cai, "Detection of glucose based on direct electron transfer reaction of glucose oxidase immobilized on highly ordered polyaniline nanotubes," Analytical Chemistry, vol. 81, no. 4, pp. 1638-1645, 2009.

[4] Q. Shi, P. Wang, Y. Jiang, and J. Kan, "Glucose biosensor based on polyaniline synthesized in ionic liquid," Biocatalysis and Biotransformation, vol. 27, no. 1, pp. 54-59, 2009.

[5] R. Nenkova, D. Ivanova, J. Vladimirova, and T. Godjevargova, "New amperometric glucose biosensor based on cross-linking of glucose oxidase on silica gel/multiwalled carbon nanotubes/polyacrylonitrile nanocomposite film," Sensors and Actuators B: Chemical, vol. 148, no. 1, pp. 59-65, 2010.

[6] K. R. Charan Reddy, F. Turcu, A. Schulte, A. M. Kayastha, and W. Schuhmann, "Fabrication of a potentiometric/ampero- metric bifunctional enzyme microbiosensor," Analytical Chemistry, vol. 77, no. 15, pp. 5063-5067, 2005.

[7] R. Ramya and M. V. Sangaranarayanan, "Electrochemical sensing of glucose using polyaniline nanofiber dendritesamperometric and impedimetric analysis," Journal of Applied Polymer Science, vol. 129, no. 2, pp. 735-747, 2013.

[8] S. A. Emr and A. M. Yacynych, "Use of polymer films in amperometric biosensors," Electroanalysis, vol. 7, no. 10, pp. 913-923, 1995.

[9] M. A. Rahman, P. Kumar, D.-S. Park, and Y.-B. Shim, "Electrochemical sensors based on organic conjugated polymers," Sensors, vol. 8, no. 1, pp. 118-141, 2008.

[10] M. Gerard, A. Chaubey, and B. D. Malhotra, "Application of conducting polymers to biosensors," Biosensors \& Bioelectronics, vol. 17, no. 5, pp. 345-359, 2002.

[11] J.-C. Vidal, E. Garcia-Ruiz, and J.-R. Castillo, "Recent advances in electropolymerized conducting polymers in amperometric biosensors," Microchimica Acta, vol. 143, no. 2-3, pp. 93111, 2003.

[12] V. Saxena and B. D. Malhotra, Handbook of Polymers in Electronics-PDF Free Download, Epdf.Pub. (n.d.)July 2020, https://epdf.pub/handbook-of-polymers-in-electronics.html.

[13] B. D. Malhotra, A. Chaubey, and S. P. Singh, "Prospects of conducting polymers in biosensors," Analytica Chimica Acta, vol. 578, no. 1, pp. 59-74, 2006.

[14] E. T. Kang, K. G. Neoh, and K. L. Tan, "Polyaniline: a polymer with many interesting intrinsic redox states, Scopus," 1998, July 2020, https://scholarbank.nus.edu.sg/handle/10635/ 67520 .

[15] A. Kausaite-Minkstimiene, V. Mazeiko, A. Ramanaviciene, and A. Ramanavicius, "Enzymatically synthesized polyaniline layer for extension of linear detection region of amperometric glucose biosensor," Biosensors \& Bioelectronics, vol. 26, no. 2, pp. 790-797, 2010.

[16] L. Shi, Y. Xiao, and I. Willner, "Electrical contacting of glucose oxidase by DNA-templated polyaniline wires on surfaces," Electrochemistry Communications, vol. 6, no. 10, pp. 10571060, 2004.

[17] K. Grennan, A. J. Killard, C. J. Hanson, A. A. Cafolla, and M. R. Smyth, "Optimisation and characterisation of biosensors based on polyaniline," Talanta, vol. 68, no. 5, pp. 1591-1600, 2006.

[18] S. Stafström, J. L. Brédas, A. J. Epstein et al., "Polaron lattice in highly conducting polyaniline: theoretical and optical studies," Physical Review Letters, vol. 59, no. 13, pp. 14641467, 1987.

[19] M. Stočes, K. Kalcher, I. Švancara, and K. Vytřas, “A new biosensor for glucose based on carbon paste and enzyme immobilized onto the polyaniline film," International Journal of Electrochemical Science, vol. 6, p. 10, 2011.

[20] J. Lai, Y. Yi, P. Zhu et al., "Polyaniline-based glucose biosensor: a review," Journal of Electroanalytical Chemistry, vol. 782, pp. 138-153, 2016.

[21] W. Yan, X. Feng, X. Chen, W. Hou, and J.-J. Zhu, “A super highly sensitive glucose biosensor based on $\mathrm{Au}$ nanoparticles-[email protected] hybrid material," Biosensors \& Bioelectronics, vol. 23, no. 7, pp. 925-931, 2008.

[22] Y.-Y. Horng, Y.-K. Hsu, A. Ganguly, C.-C. Chen, L.-C. Chen, and K.-H. Chen, "Direct-growth of polyaniline nanowires for enzyme-immobilization and glucose detection," Electrochemistry Communications, vol. 11, no. 4, pp. 850-853, 2009. 
[23] W.-Z. Jia, Y.-L. Hu, Y.-Y. Song, K. Wang, and X.-H. Xia, "Highly selective amperometric glucose microdevice derived from diffusion layer gap electrode," Biosensors \& Bioelectronics, vol. 23, no. 6, pp. 892-898, 2008.

[24] T. Kohma, D. Oyamatsu, and S. Kuwabata, "Preparation of selective micro glucose sensor without permselective membrane by electrochemical deposition of ruthenium and glucose oxidase," Electrochemistry Communications, vol. 9, no. 5, pp. 1012-1016, 2007.

[25] R. A. Alberty and R. J. Silbey, Physical Chemistry, Wiley, New York, 2nd ed. edition, 1997.

[26] “KASA Software Ltd,” 2005, http://www.casaxps.com.

[27] M. Iram, C. Guo, H. Liu, and A. Ishfaq, "Highly ordered mesostructured silica spheres as template for polyaniline nanofibres: synthesis, characterisation and their electrochemical properties," Journal of Experimental Nanoscience, vol. 7, no. 1, pp. 27-41, 2012.

[28] J. C. Cooper and E. A. H. Hall, "Electrochemical response of an enzyme-loaded polyaniline film," Biosensors \& Bioelectronics, vol. 7, no. 7, pp. 473-485, 1992.

[29] W.-C. Chen, T.-C. Wen, and A. Gopalan, "Negative capacitance for polyaniline: an analysis via electrochemical impedance spectroscopy," Synthetic Metals, vol. 128, no. 2, pp. 179-189, 2002.

[30] S. Golczak, A. Kanciurzewska, M. Fahlman, K. Langer, and J. J. Langer, "Comparative XPS surface study of polyaniline thin films," Solid State Ionics, vol. 179, no. 39, pp. 22342239, 2008

[31] A. A. Syed and M. K. Dinesan, "Review: Polyaniline-A novel polymeric material," Talanta, vol. 38, no. 8, pp. 815-837, 1991.

[32] S. Liu, D. Liu, and Z. Pan, "The effect of polyaniline (PANI) coating via dielectric-barrier discharge (DBD) plasma on conductivity and air drag of polyethylene terephthalate (PET) yarn," Polymers, vol. 10, no. 4, p. 351, 2018.

[33] J.-G. Shin, C.-S. Park, E. Y. Jung, B. J. Shin, and H.-S. Tae, "Synthesis of a polyaniline nanoparticle using a solution plasma process with an Ar gas bubble channel," Polymers, vol. 11, no. 1, p. 105, 2019.

[34] A. P. Monkman and P. Adams, "Optical and electronic properties of stretch-oriented solution-cast polyaniline films," Synthetic Metals, vol. 40, no. 1, pp. 87-96, 1991.

[35] D. S. Bindra, Y. Zhang, G. S. Wilson et al., "Design and in vitro studies of a needle-type glucose sensor for subcutaneous monitoring," Analytical Chemistry, vol. 63, no. 17, pp. 1692-1696, 2002.

[36] G. Liao, "Green preparation of sulfonated polystyrene/polyaniline/silver composites with enhanced anticorrosive properties," International Journal of Chemistry, vol. 10, no. 1, pp. 81-86, 2018.

[37] A. Harper and M. R. Anderson, "Electrochemical glucose sensors-developments using electrostatic assembly and carbon nanotubes for biosensor construction," Sensors, vol. 10, no. 9, pp. 8248-8274, 2010.

[38] A. Kausaite-Minkstimiene, V. Mazeiko, A. Ramanaviciene, and A. Ramanavicius, "Evaluation of amperometric glucose biosensors based on glucose oxidase encapsulated within enzymatically synthesized polyaniline and polypyrrole," Sensors and Actuators B: Chemical, vol. 158, no. 1, pp. 278-285, 2011.
[39] A. Kausaite-Minkstimiene, V. Mazeiko, A. Ramanaviciene, Y. Oztekin, A. Osman Solak, and A. Ramanavicius, "Evaluation of some redox mediators in the design of reagentless amperometric glucose biosensor," Electroanalysis, vol. 26, no. 7, pp. 1528-1535, 2014.

[40] Y. Oztekin, A. Ramanaviciene, Z. Yazicigil, A. O. Solak, and A. Ramanavicius, "Direct electron transfer from glucose oxidase immobilized on polyphenanthroline-modified glassy carbon electrode," Biosensors \& Bioelectronics, vol. 26, no. 5, pp. 2541-2546, 2011. 